\title{
Erratum to: Transitions between the Arabidopsis-type and the human-type telomere sequence in green algae (clade Caudivolvoxa, Chlamydomonadales)
}

\author{
Jana Fulnečková ${ }^{1,2} \cdot$ Tereza Ševčíková $^{3} \cdot$ Alena Lukešová $^{4} \cdot$ Eva Sýkorováa $^{1,2}$
}

Published online: 27 January 2016

(C) Springer-Verlag Berlin Heidelberg 2016

\section{Erratum to: Chromosoma}

DOI: 10.1007/s00412-015-0557-2

The original version of this article inadvertently contained mistake in the "Acknowledgement Section".

\section{Acknowledgements}

We are grateful to Mrs. Jedličková and Mrs. Šipková (Institute of Biophysics) and Ms. Bícová (Institute of Soil Biology) for algal cultivation and excellent technical help and also to members of Life Science Research Centre, University of Ostrava, for useful comments on the phylogeny reconstruction.

This work was supported by the Czech Science Foundation (13-06595S, 13-33039S), project CEITEC (CZ.1.05/1.1.00/02.0068) of the European Regional Development Fund, project TEWEP LO1208 of the National Feasibility Programme I of the Czech Republic, and by the Academy of Sciences of the Czech Republic (RVO 68081707).

The online version of the original article can be found at http://dx.doi.org/ 10.1007/s00412-015-0557-2.

Eva Sýkorová

evin@ibp.cz

1 Institute of Biophysics, Academy of Sciences of the Czech Republic, v.v.i., Královopolská 135, CZ-61265 Brno, Czech Republic

2 Faculty of Science, and CEITEC - Central European Institute of Technology, Masaryk University, Kamenice 5,

CZ-62500 Brno, Czech Republic

3 Department of Biology and Ecology, Life Science Research Centre \& Institute of Environmental Technologies, Faculty of Science, University of Ostrava, Chittussiho 10, CZ-71000 Ostrava, Czech Republic

4 Institute of Soil Biology, Biology Centre Academy of Sciences of the Czech Republic, v.vi., Na Sádkách 7, CZ-37005 České

Budějovice, Czech Republic 